\title{
Malakoplakia of the prostate: A report of two cases and a review of the literature
}

\section{J. MCCLURE}

From the Department of Pathology, The Queen's University of Belfast, Institute of Pathology, Grosvenor Road, Belfast, Northern Ireland, UK

SUMmARY Two cases of malakoplakia of the prostate are documented, bringing the total described in the world literature to 15 . This literature is reviewed, and typical features of the condition are established. The majority of the cases have had proven previous episodes of Escherichia coli infection of the urinary tract, but bacilliform organisms have yet to be demonstrated in the diseased prostatic tissue. Five of the reported cases have also had important additional disease, including three instances of malignant lung tumour. Finally, it is emphasised that recognition of prostatic malakoplakia as an entity will prevent its confusion with prostatic carcinoma.

Malakoplakia is a chronic inflammatory condition described by Michaelis and Gutmann (1902) and characterised by von Hansemann (1903). Typically, there are aggregations of macrophages (von Hansemann cells) containing round, often concentrically laminated, basophilic intracytoplasmic inclusions (5-10 $\mu \mathrm{m}$ in diameter). These Michaelis-Gutmann (M-G) bodies usually contain calcium salts and, less frequently, iron. Malakoplakia is usually associated with a coliform infection, and recent ultrastructural studies have been interpreted as showing intact and degenerating bacteria within phagolysosomal bodies in the cytoplasm of the von Hansemann cells (McClurg et al., 1973; Lou and Teplitz, 1974).

The most common site of involvement by malakoplakia is the urinary bladder, but in the past 20 years examples of the disease affecting extravesical sites have been reported with increasing frequency. Some of these cases have presented initial diagnostic and therapeutic difficulties because of failure to recognise the disease process and its essentially benign nature.

Malakoplakic involvement of the prostate was initially described by Carruthers in 1959. Rhodes and Wittman (1977) believed that they had reported the sixth case, but a careful review of the world literature revealed 13 reported cases (Carruthers, 1959; Coup, 1976; Doury et al., 1977; Ferreira and Alvarenga, 1976; Goldman, 1965; Hoffmann and Garrido, 1964; Kerr et al., 1972; Konnak and Hart, 1976; Lou and Teplitz, 1974; McClure et al., 1977; Maróti et al.,

Received for publication 27 November 1978
1975, 1976; Rhodes and Wittmann, 1977; Rubenstein and Bucy, 1977; Sterrett et al., 1975). In this report two additional cases are presented to make a total of 15 . The world literature is therefore reviewed, and the typical features and associations of prostatic malakoplakia are discussed.

\section{Case reports}

CASE 1

A 72-year-old man presented with a history of increasing difficulty of urination, frequency, and nocturia for several years. There had been one episode of urinary infection during which urine culture revealed a significant growth of Escherichia coli. There was nothing of relevance in the past medical history other than a mild maturity-onset diabetes mellitus controlled by diet. Clinical examination revealed an enlarged prostate. Prostatectomy was performed and a prostatic mass weighing $20 \mathrm{~g}$ was submitted for histological examination. There was a background of benign nodular hyperplasia. Many fragments contained circular foci (Fig. 1) of cells with small, dark, eccentric nuclei and abundant granular cytoplasm (von Hansemann cells). Many of these cells contained Michaelis-Gutmann (M-G) bodies, which were generally round basophilic structures, 5-10 $\mu \mathrm{m}$ in diameter, showing concentric laminations (Fig. 2). These reacted consistently with the alizarin red $S$ technique for calcium salts and equally with the von Kossa method for anionic companions of calcium. The M-G bodies were 


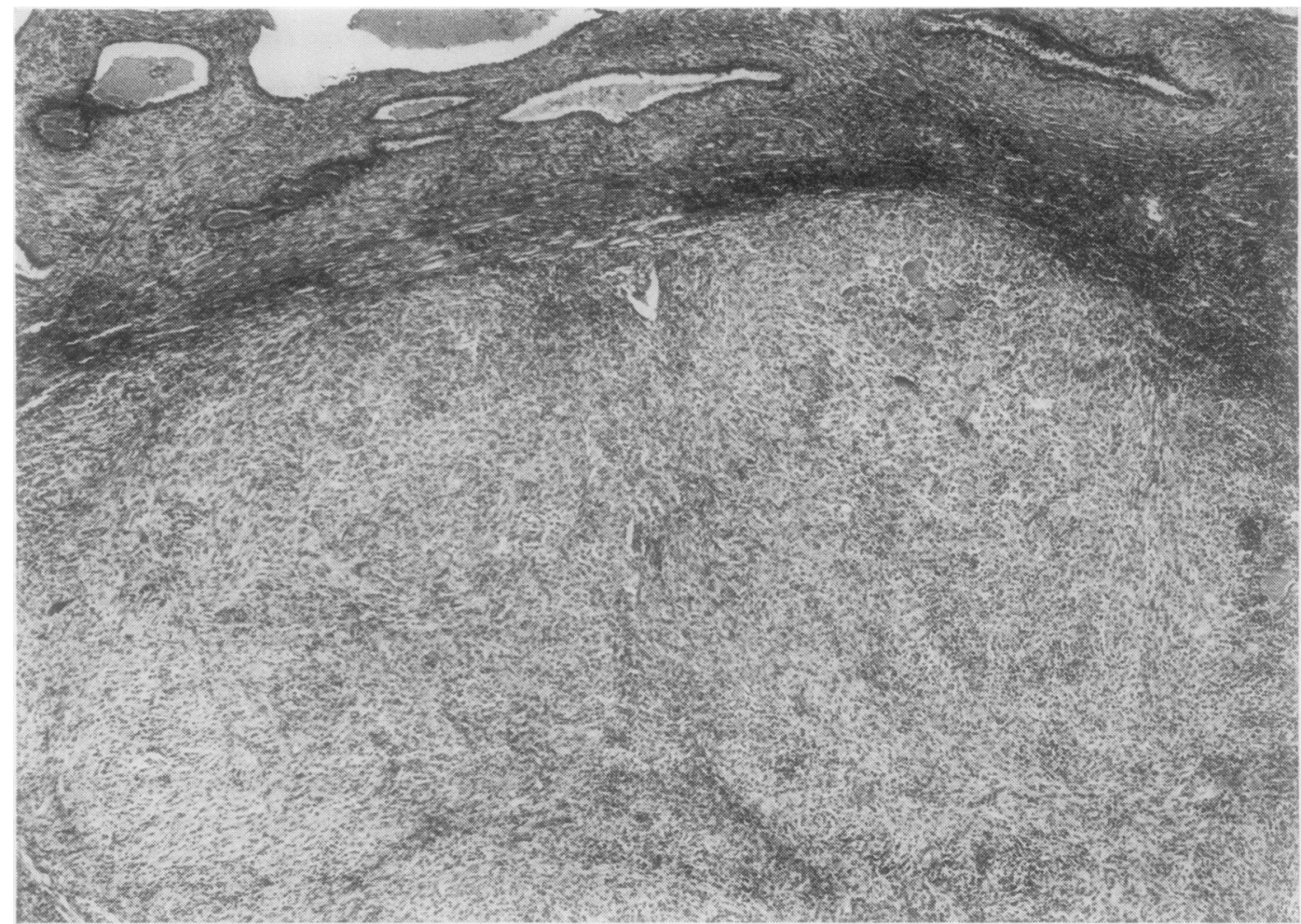

Fig. 1 Nodules of malakoplakic tissue in prostate. Haematoxylin and eosin $\times 40$.

strongly PAS-positive, but only an occasional body reacted weakly with Perl's Prussian blue.

\section{CASE 2}

A 66-year-old man presented with a history of increasing difficulty of urination and frequency for several years. There had been several episodes of urinary tract infection proved by cultures of significant numbers of $E$. coli. Nine years before the current admission he had had a right pneumonectomy for a moderately well differentiated squamous carcinoma of the bronchus. There was no evidence of either residual or recurrent tumour.

Review of the pneumonectomy specimen sustained the original diagnosis. This patient was also a mild maturity-onset diabetic.

Prostatectomy was performed because of enlargement of the gland. Histologically, the biopsy showed a benign nodular hyperplasia. In many areas there was an accumulation of von Hansemann cells individually containing $\mathrm{M}-\mathrm{G}$ bodies. The staining reactions of these were similar to those of case 1 with strongly positive alizarin red S, von Kossa, and PAS reactions and a weakly positive Perl's Prussian blue reaction.

\section{Discussion}

The mode of presentation of these two cases is similar. Both had obstructive lower urinary tract symptoms associated with prostatomegaly. There were episodes of proven urinary tract infections, and the diagnosis of malakoplakia was entirely unsuspected clinically. The malakoplakic tissue in each showed typical morphological and histochemical features.

Of the total of 15 reported cases, the ages of 14 are known. The average age at presentation was 64.5 (range 49-85) years. Twelve cases presented with obstructive lower urinary tract symptoms; 11 of these had prostatomegaly and one had a 'small obstructive' prostate (Ferreira and Alvarenga, 1976). In another patient (Kerr et al., 1972), a prostatectomy was performed, and although no clinical details were given, it is likely that this was for prostatic enlargement.

Two cases had normal-sized prostates, and both of these had malignant tumours-a squamous carcinoma of a peripheral bronchus (Goldman, 1965) and a metastasising bronchial carcinoid (McClure et al., 1977). Obstructive urinary symptoms were not 


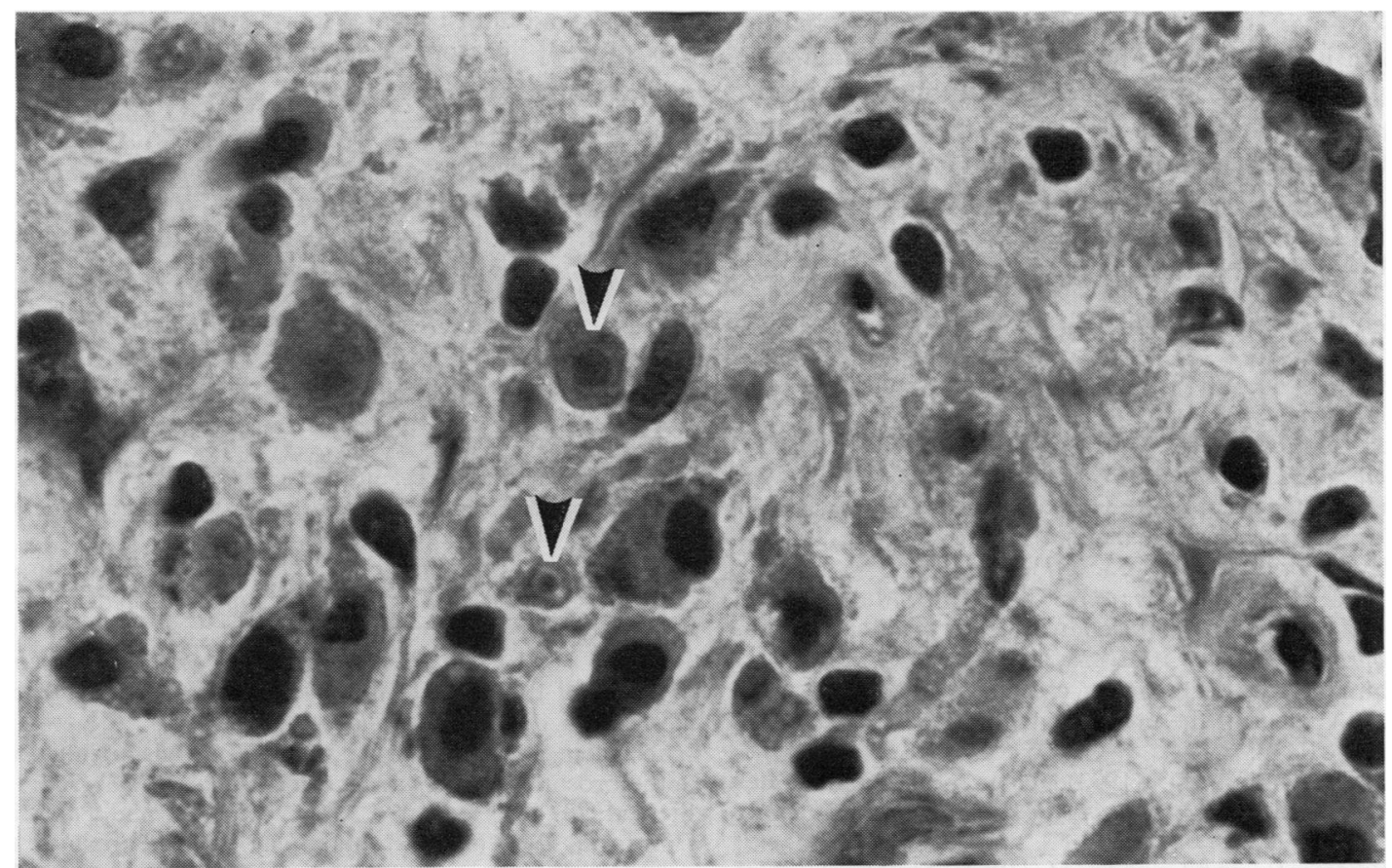

Fig. 2 Malakoplakia of prostate. Typical $M-G$ bodies are arrowed. $H$ and $E \times 400$.

present in either, but the latter had an $E$. coli urinary infection and the former $E$. coli abscesses of the retroperitoneum.

In 12 cases the disease was restricted to the prostate. In one case there was involvement of urinary bladder, bladder neck, and prostatic ducts (Hoffmann and Garrido, 1964), in another involvement of bladder and prostate (Goldman, 1965), and in the third, involvement of testis, kidney, retroperitoneum, and prostate (McClure et al., 1977). These latter two cases were referred to above, being in association with malignant tumours.

In 11 cases, urinary infection was sought and proven, and $E$. coli was cultured in significant numbers in each. In the remaining four cases, no indication is given as to whether or not infection was actively sought. In seven cases organisms were sought in the prostatic tissue (by electron microscopy in four of these). Organisms were not demonstrated in any of these cases. Thus there is an obvious frequent association of prostatic malakoplakia with urinary tract infection by $E$. coli, but the organism has yet to be demonstrated in an intact form in prostatic diseased tissues. This may be due to the fact that the disease is probably being studied at a relatively late stage in its evolution.

In the literature, five of the reported cases had other major disease processes: (a) squamous car- cinoma of a peripheral bronchus (Goldman, 1965), (b) metastasising bronchial carcinoid (McClure et al., 1977), (c) E. coli septicaemia (Sterrett et al., 1975), (d) pulmonary abscess, renal calculi, and a prolonged history of repeated urinary infections (Rhodes and Wittmann, 1977), (e) renal transplant and immunosuppressive treatment (Konnak and Hart, 1976). This latter case had been treated with prednisone and azathioprine, and in the case reported by McClure et al. (1977) there was proven hypersteroidism as a consequence of ectopic ACTH production by the bronchial carcinoid. One can only speculate that hypersteroidism may so alter lysosomal reactivity as to be influential in the pathogenesis of malakoplakia. It is also interesting that the second case documented in this report had a bronchial squamous carcinoma although there is no evidence in that case of hypersteroidism. At any rate, three of the 15 reported cases of prostatic malakoplakia have been in patients who have also had malignant bronchial tumours.

An important reason for describing and defining prostatic malakoplakia is that it has been diagnosed initially in three instances as a carcinoma (Coup, 1976; Ferreira and Alvarenga, 1976; Rubenstein and Bucy, 1977). An awareness of the condition and the detection of typical M-G bodies will allow the correct diagnosis to be made. Similarly, prostatic malako- 
plakia may be distinguished from granulomatous prostatitis. This latter has been defined as a chronic granulomatous inflammation without a specific cause and often related to distended or disrupted ducts (Tanner and McDonald, 1943). It may well be that cases of malakoplakia have been diagnosed as granulomatous prostatitis due to lack of awareness of the former entity.

\section{References}

Carruthers, N. C. (1959). Malakoplakia; report of a case. Canadian Journal of Surgery, 2, 213-214.

Coup, A. J. (1976). Malakoplakia of the prostate. Journal of Pathology, 119, 119-121.

Doury, J. C., Berruti, A., Garron, A., and Georges, A. J. (1977). Un cas de malacoplasie prostatique. Semaine de Hôpitaux de Paris, 53, 2273-2275.

Ferreira, A. A., and Alvarenga, M. (1976). Malacoplakia of the prostate confused with clear cell carcinoma. Journal of Urology, 116, 828-829.

Goldman, R. L. (1965). A case of malacoplakia with involvement of the prostate gland. Journal of Urology, 93, 407-410.

von Hansemann, D. (1903). Über Malakoplakie der Harnblase. Virchows Archiv für pathologische Anatomie, 173, 302-308.

Hoffmann, E., and Garrido, M. (1964). Malakoplakia of the prostate: report of a case. Journal of Urology, 92, 311-313.

Kerr, J. F. R., Gaffney, T. J., McGeary, H. M., Duhig, R. E. T., and Nicolaides, N. J. (1972). Malakoplakia: an electron-microscope and chemical study. Journal of Pathology, 107, 289-294.

Konnak, J. W., and Hart, W. R. (1976). Malacoplakia of the prostate in an immunosuppressed patient. Journal of Urology, 116, 830-832.

Lou, T. Y., and Teplitz, C. (1974). Malakoplakia, patho- genesis and ultrastructural morphogenesis: a problem of altered macrophage (phagolysosomal) response. Human Pathology, 5, 191-207.

McClure, J., Hadden, D. R., Mudd, D. G., and Parks, T. G. (1977). Adrenocortical hyperactivity with disseminated malacoplakia. Journal of Clinical Pathology, 30, 206-211.

McClurg, F. V., D'Agostino, A. N., Martin, J. H., and Race, G. J. (1973). Ultrastructural demonstration of intracellular bacteria in three cases of malakoplakia of the bladder. American Journal of Clinical Pathology, 60, 780-788.

Maróti, M., Rohonyi, B., and Vecsey, D. (1975). Malacoplakia of the prostate gland. (Hungarian.) Orvosi Hetilap, 116, 23-24.

Maróti, M., Rohonyi, B., and Vecsey, D. (1976). ProstataMalakoplakie. Zeitschrift für Urologie und Nephrologie, 69, 809-810.

Michaelis, L., and Gutmann, C. (1902). Uber Einschlüsse in Blasentumoren. Zeitschrift für klinische Medizin, 47, 208-215.

Rhodes, R. H., and Wittmann, A. L. (1977). Malacoplakia of the prostate following chronic urinary tract infection. Journal of Urology, 117, 808-810.

Rubenstein, M., and Bucy, J. G. (1977). Malacoplakia of the prostate. Southern Medical Journal, 70, 351-352.

Sterrett, G. F., Heenan, P. J., Wyche, P., and Papadimitriou, J. M. (1975). Malakoplakia of the prostate: a morphological and biochemical study. Pathology, 7, 139-147.

Tanner, F. H., and McDonald, J. R. (1943). Granulomatous prostatitis: a histologic study of a group of granulomatous lesions collected from prostate glands. Archives of Pathology, 36, 358-370.

Requests for reprints to: Dr J. McClure, Division of Tissue Pathology, Institute of Medical and Veterinary Science, Box 14, Rundle Street Post Office, Adelaide, South Australia, 5000, Australia. 